\title{
Optical Diagnostics of RF Argon and Xenon Magnetron Discharges
}

M.F. Dony $\left({ }^{1}\right)$, F. Debal $\left({ }^{1}\right)$, M. Wautelet $\left({ }^{1, *}\right)$, J.P. Dauchot $\left({ }^{1}\right)$, M. Hecq $\left({ }^{1}\right)$, J. Bretagne $\left({ }^{2}\right)$, P. Leray $\left({ }^{2}\right)$ and A. Ricard $\left({ }^{3}\right)$

$\left({ }^{1}\right)$ Laboratoire de Chimie Inorganique et Analytique Université de Mons Hainaut, 23 avenue Maistriau, 7000 Mons, Belgium

$\left({ }^{2}\right)$ Laboratoire de Physique des Gaz et Plasmas, Bâtiment 212, Université Paris-Sud-CNRS, 91405 Orsay, France

$\left({ }^{3}\right)$ CPAT-Université Paul Sabatier, 118 route de Narbonne, 31062 Toulouse, France

(Received 29 January 1997, revised 21 May 1997, accepted 27 May 1997)

PACS.52.20 $\mathrm{j}$ - Elementary processes in plasma

PACS.82.40.Ra - Plasma reactions (including flowing a afterglow and electric discharges)

\begin{abstract}
A comparison of magnetron discharges in $\mathrm{Ar}$ and Xe gases with $\mathrm{Al}$ and $\mathrm{BN}$ targets has shown that a similar electron kinetic is producing about the same quantity of $\mathrm{Ar}$ and Xe metastable atoms: $(1-3) \times 10^{10} \mathrm{~cm}^{-3}$ at gas pressures of 25 and $100 \mathrm{mTorr}$ and RF powers, $\mathrm{W}$, from 5 to 50 watts. The electron density is varying as $W^{\frac{1}{2}}$ in the two gases. The sputtering yields of $\mathrm{Al}$ and $\mathrm{BN}$ targets are lower in Xe than in $\mathrm{Ar}$, by factors of 1.1-1.2 for $\mathrm{Al}$ and of 3 for $\mathrm{BN}$,
\end{abstract}

Résumé. - La comparaison de décharges magnétrons dans des gaz d'argon et de xénon, avec des cibles en $\mathrm{Al}$ et $\mathrm{BN}$ indique que des quantités équivalentes d'argon et de xénon métastables sont produites, à savoir $(1-3) \times 10^{10} \mathrm{~cm}^{-3}$ à des pressions de 25 et $100 \mathrm{~m}$ Torr et des puissances $\mathrm{RF}, \mathrm{W}$, de 5 à 50 watts. La densité électronique varie comme $W^{\frac{1}{2}}$ dans les deux cas. Les taux de pulvérisation de cibles d'Al et de BN sont plus faibles dans le Xe que dans l'Ar, d'un facteur $1,1-1,2$ pour $\mathrm{Al}$ et 3 pour $\mathrm{BN}$.

\section{Introduction}

Magnetron sputtering is widely used for thin film deposition, in various technological fields [1]. Despite the large number of applications, only a few studies are devoted to the diagnostic of such magnetised plasmas. Results from emission and absorption spectroscopy of argon magnetron discharges with an aluminium target have been recently reported $[2,3]$. Variations of $\mathrm{Ar}, \mathrm{Ar}^{+}$and $\mathrm{Al}$ line intensities, of $\mathrm{Ar}\left({ }^{3} \mathrm{P}_{2},{ }^{3} \mathrm{P}_{0}\right)$ metastable and of $\mathrm{Ar}\left({ }^{3} \mathrm{P}_{1},{ }^{1} \mathrm{P}_{1}\right)$ resonant atom densities and of $\mathrm{Al}$ ground state densities have been obtained by changing numerous parameters such as the target thickness, gas discharge pressure, electric power and distance from the target.

$\left(^{*}\right)$ Author for correspondence (e-mail: michel.wautelet@umh.ac.be) 


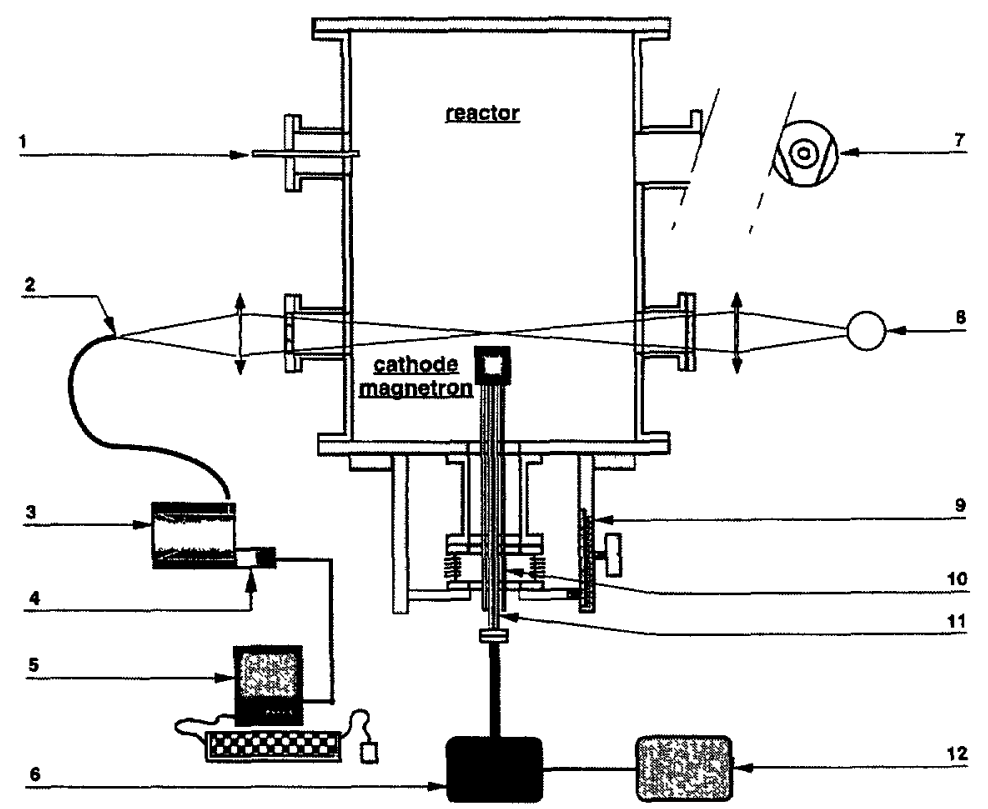

Fig. 1. - Experimental set-up of magnetron discharge with optical arrangement for emission and resonant absorption spectroscopy. 1. gas inlet; 2. optical fiber; 3. spectrometer; 4. photomultiplier; 5. PC control; 6. matching network; 7. turbomolecular pump; 8. optical source; 9 . vernier; 10 cooling; 11 copper conductor; 12 . RF generator $-13.56 \mathrm{MHz}$.

Magnetron discharges in Xe are presently of great interest to study the sputtering of BN ceramics in Xe ion sources for Stationary Plasma Thrusters (SPT) [4].

In the present work, the Xe radiative states and the Xe metastable atoms in magnetron Xe discharges are studied by emission and absorption spectroscopy in a similar way as for argon. The results are analysed for $\mathrm{Al}$ and $\mathrm{BN}$ target cathodes.

\section{Experimental Setup}

The experimental setup has been detailed elsewhere $[2,3]$. It is reproduced in Figure 1. The magnetron cathode can be made in aluminium (thickness $5 \mathrm{~mm}$ ) or in a BN ceramic (thickness $3 \mathrm{~mm}$ ) of diameters $33 \mathrm{~mm}$. The cathode is located inside a stainless steel chamber at the ground potential which acts as the anode of magnetron discharge. Also the cathode is surrounded by a guard ring at ground potential.

On the cathode surface, the magnetic induction is such that the electrons are confined in the plasma at about $1 \mathrm{~cm}$ in front of the surface. After a base pressure lower than $10^{-6}$ Torr is achieved, the Ar or Xe gas is introduced to maintain a pressure ranging from 3 to 150 mTorr. The $13.56 \mathrm{MHz}$ RF power can vary from 1 to 50 watts.

As shown in Figure 1, the plasma is analysed by emission spectroscopy vza a quartz optical fiber bundle (diameter $1 \mathrm{~mm}$ ). The optical absorption is performed with an optical source which can be a Philips Ar or Xe lamp or a Perkin-Elmer lamp.

Two optical lenses $\left(L_{1}\right.$ and $L_{2}$ in Fig.1) focused the source light beam and collected the plasma light on the optical fiber with a spatial resolution which is estimated to be $2 \mathrm{~mm}$ for emission and absorption measurements. The spectral line intensities in emission and absorption 


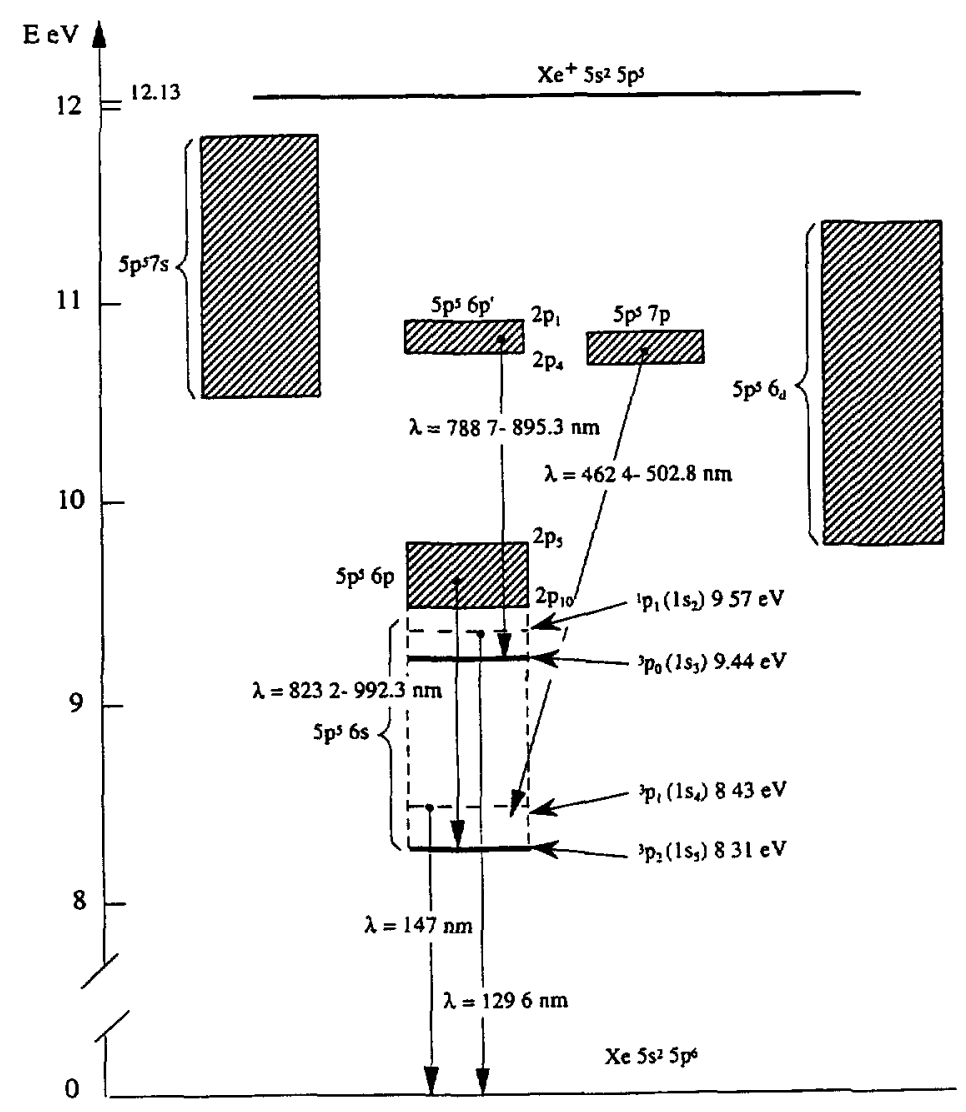

Fig. 2. - Xe energy levels.

are recorded by means of a Jobin-Yvon HR 1000 spectrometer with an Hamamatsu $166 \mathrm{UH}$ photomultiplier for the $\mathrm{Ar}$ and $\mathrm{Al}$ lines and by means of a chromex $2501 \mathrm{~S}$ monochromator with a CCD camera for the Xe lines.

\section{Density of $\mathrm{Xe}\left({ }^{3} \mathrm{P}_{2}\right)$ Metastable Atoms}

The Xe energy levels are reproduced in Figure 2. The first excited level configuration $\left(5 p^{5} 6 s\right)$ at about $6 \mathrm{eV}$ contains two metastable $\left({ }^{3} \mathrm{P}_{2},{ }^{3} \mathrm{P}_{0}\right)$ and two resonant $\left({ }^{3} \mathrm{P}_{1},{ }^{1} \mathrm{P}_{1}\right)$ levels.

The density of $\mathrm{Xe}\left({ }^{3} \mathrm{P}_{2}\right)$ can be determined by the resonant absorption method of MitchelZemansky as it is detailed in references [2] and [3]. The absorption coefficient $A_{L}$ of a spectral line along the absorption length is given by:

$$
A_{L}=1-I_{\mathbf{t}} / I_{0}
$$

where $I_{\mathrm{t}}$ and $I_{0}$ are the transmitted and incident intensity of the chosen Xe (6p-6s) line.

In the present absorption measurements, $I_{0}$ is recorded without plasma, $I_{\mathrm{t}}$ is deduced by subtracting the total intensity $\left(I_{t+p}\right)$ of both transmitted from the lamp $\left(I_{t}\right)$ and emitted from the plasma $\left(I_{\mathrm{p}}\right)$ and the $I_{\mathrm{p}}$ plasma intensity alone as the lamp is masked. 
Table I. - Oscullator strengths for the most intense spectral lines of the $X e\left(5 p^{5} 6 s-5 p^{5} 6 p\right)$ transitions.

\begin{tabular}{|c|c|c|c|c|c|c|c|}
\hline Transitions & ${ }^{1} \mathrm{~S}_{5}-{ }^{2} \mathrm{P}_{6}$ & ${ }^{1} \mathrm{~S}_{4}-{ }^{2} \mathrm{P}_{5}$ & ${ }^{1} \mathrm{~S}_{2}-{ }^{2} \mathrm{P}_{3}$ & ${ }^{1} \mathrm{~S}_{5}-{ }^{2} \mathrm{P}_{7}$ & ${ }^{1} \mathrm{~S}_{5}-{ }^{2} \mathrm{P}_{8}$ & ${ }^{1} \mathrm{~S}_{5}-{ }^{2} \mathrm{P}_{10}$ & ${ }^{1} \mathrm{~S}_{4}-{ }^{2} \mathrm{P}_{9}$ \\
\hline$\lambda(\mathrm{nm})$ & 823.2 & 828 & 834.7 & 840.1 & 881.9 & 980 & 992.3 \\
\hline $\begin{array}{c}\text { Oscillator strengths } \\
(5,6)\end{array}$ & 0.227 & 0.103 & 0.337 & 0.0146 & 0.485 & 0.207 & 0.428 \\
\hline
\end{tabular}

$A_{L}$ is related to the optical thickness $k_{\sigma_{0}} L$, which is given by the following equation:

$$
k_{\sigma_{0}} L=8.25 \times 10^{-13} \frac{f}{\delta \sigma_{1 / 2}^{\mathrm{P}}} L n_{X e}\left({ }^{3} \mathrm{P}_{2}\right)
$$

(f-oscillator strength of the absorbing levels, whose the Doppler broadening in the plasma is $\delta \sigma_{1 / 2}^{P}, L$-absorption length and $n_{\mathrm{Xe}}\left({ }^{3} \mathrm{P}_{2}\right)$, density of metastable atoms), via the following factor:

$$
\alpha=\frac{\delta \sigma_{1 / 2}^{\mathrm{S}}}{\delta \sigma_{1 / 2}^{\mathrm{P}}}
$$

$\left(\delta \sigma_{1 / 2}^{\mathrm{S}}\right.$ source line broadening). $k_{\sigma_{0}}$ and $\delta \sigma_{1 / 2}$ are in $\mathrm{cm}^{-1}, L$ is in $\mathrm{cm}$ and $n$ in $\mathrm{cm}^{-3} . f$ is dimensionless.

The oscillator strengths for several spectral lines originating from the $\mathrm{Xe}\left({ }^{3} \mathrm{P}_{2},{ }^{3} \mathrm{P}_{1},{ }^{1} \mathrm{P}_{1}\right)$ levels are reproduced in Table I following references [5] and [6].

We have checked the broadenings of these spectral lines emitted from the Philips lamp by assuming, first a Doppler broadening at $T=300 \mathrm{~K}$ and second, a self broadening for a density of $\mathrm{Xe}\left({ }^{3} \mathrm{P}_{2}\right)$ metastables atoms between $10^{11}$ and $10^{12} \mathrm{~cm}^{-3}$ in the lamp with a radius $R=1 \mathrm{~cm}$.

For a Doppler broadening $\left(\delta \sigma_{1 / 2}^{D}\right)$ of a spectral line (gaussian shape), the self-broadening $\delta \sigma_{1 / 2}^{\mathrm{S}}$ can be calculated by using the following equation:

$$
\frac{\delta \sigma_{1 / 2}^{\mathrm{S}}}{\delta \sigma_{1 / 2}^{\mathrm{D}}}=\left[\frac{1}{\ln 2} \ln \left(\frac{k_{\sigma_{0}} R}{\ln \left(\frac{2}{1+\exp -k_{\sigma_{0}} R}\right)}\right)\right]^{1 / 2}
$$

where $k_{\sigma_{0}}$ is calculated with equation (2).

The Xe I $823.16 \mathrm{~nm}(6 \mathrm{p}-6 \mathrm{~s})$ line is chosen to determine the $\mathrm{Xe}\left({ }^{3} \mathrm{P}_{2}\right)$ metastable density. The absorption measurements are performed outside the magnetized plasma where we assume the gas to be at room temperature. Consequently, the $\alpha$ factor is given by equation (4) where $\delta \sigma_{1 / 2}^{\mathrm{D}}=\delta \sigma_{1 / 2}^{\mathrm{P}}$. It has been found $\alpha_{8232}=1.2-2.1$.

The $L$ absorption length has been estimated by measuring $A_{L}$ versus the $z$-axial distance above the magnetron cathode [2]. It has been found that $A_{L}$ decreases versus $z$. For $\mathrm{p}=$ $25 \mathrm{mTorr}, A_{L}$ is half its maximum value, $A_{L}^{\mathrm{M}}$, for $z\left(A_{L}^{\mathrm{M}} / 2\right)=3 \pm 1 \mathrm{~cm}$, for an RF power of $50 \mathrm{~W}$. By assuming a spherical plasma, it is determined $L=d_{\mathrm{c}}+2 z\left(A_{L}^{\mathrm{M}} / 2\right)$ where $d_{\mathrm{c}}=3.3 \mathrm{~cm}$ is the cathode diameter. It is obtained $L=10 \mathrm{~cm}$ at $25 \mathrm{mTorr}, 50 \mathrm{~W}$ and $L=8 \mathrm{~cm}$ at 100 mTorr, $50 \mathrm{~W}$. With Xe, the absorption length is smaller than with Ar where $L=16 \mathrm{~cm}$ and $12 \mathrm{~cm}$ was found at 25 and $100 \mathrm{~m}$ Torr, $50 \mathrm{~W}$ respectively.

With an $\mathrm{Al}$ cathode of thickness $5 \mathrm{~mm}$, it has been determined the $\mathrm{Xe}\left({ }^{3} \mathrm{P}_{2}\right)$ values as reported in Table II, for two gas pressure (25 and $100 \mathrm{mTorr}$ ), and at a distance of $1.5 \mathrm{~cm}$ 
Table II. - Xe $\left({ }^{3} \mathrm{P}_{2}\right)$ densities for two gas pressure and the $A l$ and $B N$ cathodes, $d=1.5 \mathrm{~cm}$.

\begin{tabular}{|l|l|l|}
\hline $\mathrm{Xe}\left({ }^{3} \mathrm{P}_{2}\right) / p(\mathrm{~m}$ Torr $)$ & 25 & 100 \\
\hline Al cathode $A_{L}$ & 0.54 & 0.5 \\
$n\left(10^{10} \mathrm{~cm}^{-3}\right)$ & $1.2-2.6$ & $1.3-2.6$ \\
\hline $\mathrm{BN}$ cathode $A_{L}$ & 0.506 & 0.41 \\
$n\left(10^{10} \mathrm{~cm}^{-3}\right)$ & $1.1-2.2$ & $1-1.8$ \\
\hline
\end{tabular}

above the cathode. It is also reported in Table II, the $\mathrm{Xe}\left({ }^{3} \mathrm{P}_{2}\right)$ density values obtained with a $\mathrm{BN}$ ceramic cathode, in the same conditions as with the $\mathrm{Al}$ cathode.

It has been found constant values of $\mathrm{Xe}\left({ }^{3} \mathrm{P}_{2}\right)$ densities in the RF power range from 5 to $50 \mathrm{~W}$. It is concluded that the $\mathrm{Xe}\left({ }^{3} \mathrm{P}_{2}\right)$ atoms have reached saturated values as well as the $\operatorname{Ar}\left({ }^{3} \mathrm{P}_{2}\right)$ atoms [2] do, thus indicating that these metastables are mainly produced and destroyed by electron collisions. As previously discussed [2], the electron density disappears in the kinetic equation of metastable atom density, explaining its nearly constant value when $W$ increases.

Thus it can be concluded from Table II that the $\mathrm{Xe}\left({ }^{3} \mathrm{P}_{2}\right)$ metastable densities are not really affected as the cathode material is $\mathrm{Al}$ or $\mathrm{BN}$.

With argon discharges, in similar experimental conditions (25-100 mTorr, 5-50 watts), distances 1-3 cm from the Al cathode), it has been found $[2]\left[\operatorname{Ar}\left({ }^{3} \mathrm{P}_{2}\right)\right]=(3-6) \times 10^{10} \mathrm{~cm}^{-3}$ at $25 \mathrm{~m}$ Torr, and $\left[\operatorname{Ar}\left({ }^{3} \mathrm{P}_{2}\right)\right]=(2-3) \times 10^{10} \mathrm{~cm}^{-3}$ at 100 mTorr.

About same values of metastable densities are then obtained in Ar and Xe discharge with Al cathodes.

\section{Intensity of Radiative Species (Xenon and Sputtered Atoms)}

Intensity of Xenon and sputtered atom lines have been recorded at $1 \mathrm{~mm}$ above the cathode, at the maximum of the negative glow. The spectral line intensity $I\left(\lambda_{1 \mathrm{f}}\right)$ is related to the radiative state density $n_{\mathrm{i}}$ by

$$
I\left(\lambda_{\mathrm{lf}}\right)=c\left(\lambda_{\mathrm{lf}}\right) n_{1} A_{\mathrm{if}}
$$

where $\mathrm{i}$ and $\mathrm{f}$ are the initial and final states, $c\left(\lambda_{\text {if }}\right)$ is the spectral response of the spectrometer and $A_{1 \mathrm{f}}$ the radiative frequency. The radiative state density depends on the electron density $n_{\mathrm{e}}$ as it follows:

$$
n_{\imath}=\frac{n_{0} n_{\mathrm{e}} C^{\mathrm{l}}}{\sum_{\mathrm{f}} A_{\mathrm{lf}}+n_{\mathrm{e}} C_{\mathrm{i}}}
$$

where $C^{1}$ and $C_{\mathrm{i}}$ are the production and destruction rates by electron collisions respectively and $n_{0}$ the neutral gas density.

The radiative frequencies are about $10^{7} \mathrm{~s}^{-1}$ and $C_{1}$ is of the order $10^{-6}-10^{-7} \mathrm{~cm}^{3} \mathrm{~s}^{-1}$. In the case of magnetron discharges $n_{\mathrm{e}}<10^{12} \mathrm{~cm}^{-3}$, thus the spectral line intensity is given by:

$$
I\left(\lambda_{\mathrm{if}}\right)=K_{\mathrm{rf}} n_{0} n_{\mathrm{e}} C^{\mathrm{i}}
$$

with

$$
K_{\mathrm{lf}}=C\left(\lambda_{\mathrm{If}}\right) \frac{A_{\mathrm{lf}}}{\sum_{\mathrm{f}} A_{\mathrm{lf}}} .
$$




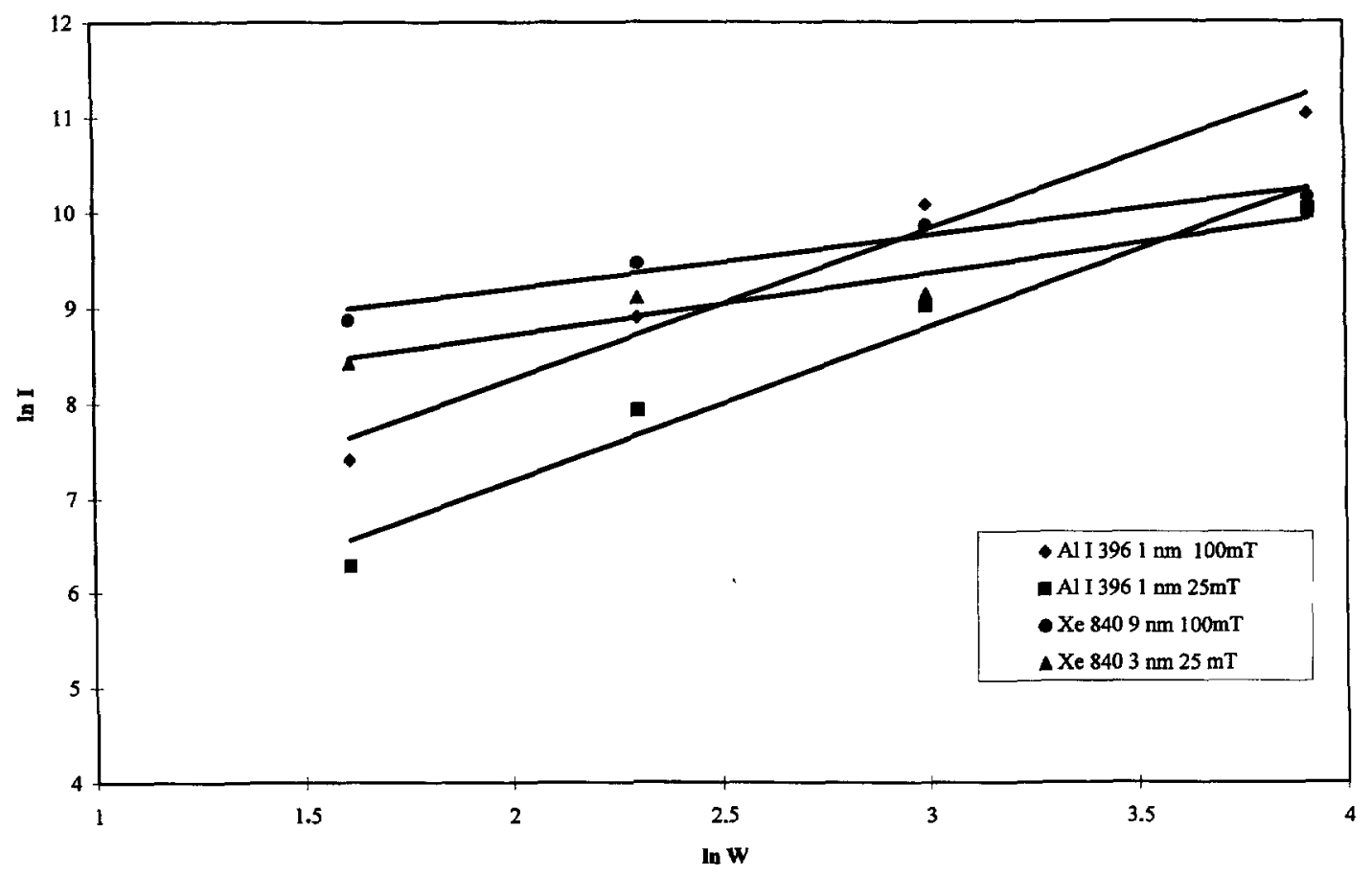

Fig. 3. - Variations of $\ln I$ versus $\ln W$ of Xe I $840.9 \mathrm{~nm}$ and Al I $396.1 \mathrm{~nm}$ lines at 25 and $100 \mathrm{mTorr}$.

Variations of $\ln I_{\lambda}$ versus $\ln W$ are reproduced in Figure 3 for the Al396.1 nm and Xe $840.9 \mathrm{~nm}$ lines at the maximum of negative glow $(1 \mathrm{~mm})$. It is deduced $I_{\lambda}=W^{\beta}$ variations with $\beta=0.5( \pm 0.03)$ for the $\mathrm{Xe}$ line and $\beta=1.9( \pm 0.5)$ for the Al line. In the case of argon, it was also found [2] a mean $\beta$ value of 0.5 for the argon lines when the excitation of radiative states is by direct electron collisions on the Ar ground state.

Then at a given Xe pressure, it can be deduced from equation $(7)$ that $I_{\lambda}(\mathrm{Xe}) \sim n_{\mathrm{e}}$, with $n_{\mathrm{e}} \sim W^{05}$ in a similar way as for Ar magnetron discharges. Such a result confirms that the $\mathrm{Xe}$ and Ar discharges have a similar electron kinetics.

The $\beta$ value for the $\mathrm{Al}$ intensity $(\beta=1.9)$ is somewhat higher in Xe than in $\mathrm{Ar}$ where $\beta=1.3-1.6$. As discussed for argon discharges [2-7], the $\mathrm{Al}$ intensity is proportional to the sputtering ion density and to the electron density and to the $\gamma_{\mathrm{Al}}$ sputtering coefficient. As $n_{\mathrm{Ar}^{+}}$or $n_{\mathrm{Xe}^{+}} \approx n_{\mathrm{e}}$, it can be written:

$$
I_{\lambda}(\mathrm{Al}) \sim \gamma_{\mathrm{Al}} n_{\mathrm{e}}^{2}
$$

(8) With $n_{\mathrm{e}} \sim W^{1 / 2}$, it is deduced $\gamma_{\mathrm{Al}}(\mathrm{Xe}) \sim W^{09}$ (to compare with $\gamma_{\mathrm{Al}}(\mathrm{Ar}) \sim W^{0.3-0.6}$ ). The variation of $\gamma_{\mathrm{Al}}$ with $W$ arises from the fact that, when $W$ increases, the cathode potential increases. The ion energy and hence the sputtering coefficient increase with increasing $W$.

The $\ln I$ versus $\ln W$ variations of $\mathrm{B}, \lambda=249.7 \mathrm{~nm}$ and $\mathrm{Ar}, \lambda=750.4 \mathrm{~nm}, 451 \mathrm{~nm}$ spectral lines at the maximum of negative glow $(1 \mathrm{~mm})$ are reproduced in Figure 4 for the 100 and 25 mTorr Ar gas pressures. The $\beta_{\text {Ar }}$ values are in the same way as previously determined with an Al target: $\beta_{\mathrm{Ar}}=0.5( \pm 0.2)$ [2]. The $\beta_{\mathrm{B}}$ value of 2.1 can be related (see Eq. (8) for the $\mathrm{B}$ line) to $\gamma_{\mathrm{B}}(\mathrm{Ar}) \sim W^{11}$ which is about twice $\gamma_{\mathrm{Al}}(\mathrm{Ar}) \sim W^{03-06}$. 


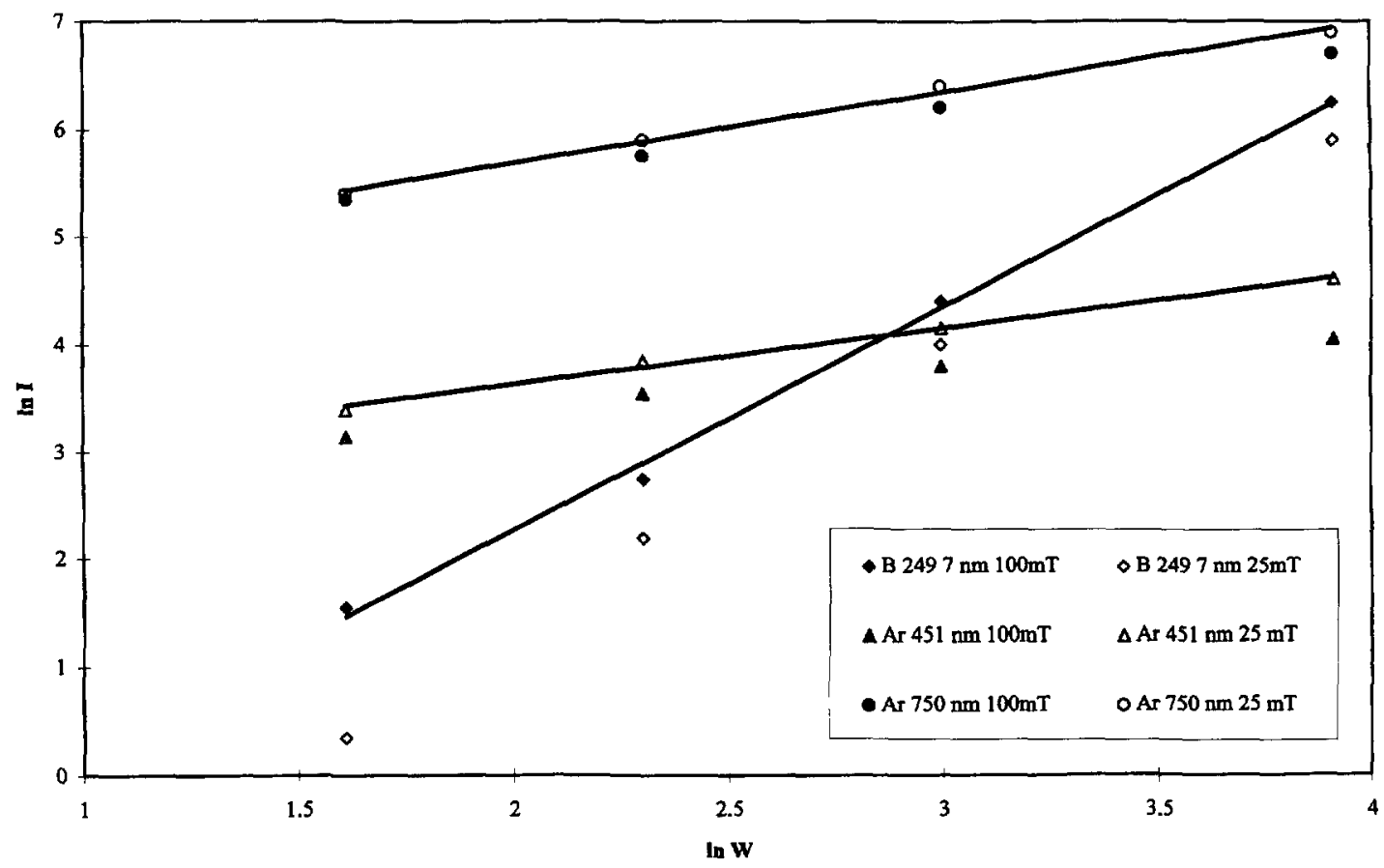

Fig. 4. - Variations of $\ln I$ versus $\ln W$ of Ar I $451 \mathrm{~nm}, 750.4 \mathrm{~nm}$ and B I $249.7 \mathrm{~nm}$ lines at 25 and 100 mTorr.

Table III. - Varnations of the intensity ratio $r=I_{\mathrm{Al}(\mathrm{Xe})} / I_{\mathrm{Al}(\mathrm{Ar})}$ of Al I 396.1 nm versus the $R F$ power in $X e$ and Ar discharges.

\begin{tabular}{|l|l|l|l|l|}
\hline$W_{\mathrm{RF}}$ (Watts) & 5 & 10 & 20 & 50 \\
\hline$r$ 25 mTorr & 0.6 & 0.8 & 0.86 & 0.91 \\
\hline$r$ 100 mTorr & 0.93 & 0.74 & 0.81 & \\
\hline
\end{tabular}

Now, if the Al I $396.1 \mathrm{~nm}$ intensity is compared in the two Ar and Xe discharge, it is found the results as reproduced in Table III for the two gas pressures: 25 and $100 \mathrm{mTorr}$ and a RF power between 5 and $50 \mathrm{~W}$. It is deduced from Table III that the Al line intensity is 10 to $20 \%$ lower in Xe than in Ar discharges.

With the BN ceramic cathode, the $\mathrm{B}, \lambda=249.7 \mathrm{~nm}$ line has been detected at $1 \mathrm{~mm}$ above the cathode. It has been found a weak intensity of the B line in Xe discharge, largely smaller than in Ar discharge although the bias voltage is higher in $\mathrm{Xe}\left(V_{\mathrm{b}}=-590 \mathrm{~V}\right.$ in Xe compared to $V_{\mathrm{b}}=-550 \mathrm{~V}$ in argon). At $25 \mathrm{~m}$ Torr $-50 \mathrm{~W}$, the ratio $r=I_{\mathrm{B}(\mathrm{Xe})} / I_{\mathrm{B}(\mathrm{Ar})}$ is equal to 0.27 .

Altogether, it is concluded that the $\mathrm{Xe}^{+}$ions have a sputtering rate lower than the $\mathrm{Ar}^{+}$ions, by a factor $0.8-0.9$ for the $\mathrm{Al}$ target and as low than 0.3 for $\mathrm{BN}$ target. 


\section{Conclusions}

Magnetron discharges in $\mathrm{Ar}$ and Xe are working with similar electron kinetics. In the same conditions of pressure, power and with two cathode targets: $\mathrm{Al}$ and $\mathrm{BN}$, it has been found about the same Ar and Xe metastable atom densities: $(1-3) \times 10^{10} \mathrm{~cm}^{-3}$ and the same electron density variations with the discharge power: $n_{\mathrm{e}} \sim W^{05}$. As it concerns the sputtering yields of $\mathrm{Al}$ and $\mathrm{BN}$ targets lower values have been determined for $\mathrm{Xe}$ as for $\mathrm{Ar}$, a factor of 1.1 to 1.2 with $\mathrm{Al}$, dropping to about 3 with $\mathrm{BN}$. It can be concluded that, for $\mathrm{BN}$ targets, sputtering with $\mathrm{Xe}$ is less effective than with $\mathrm{Ar}$

\section{References}

[1] Crill A., Cold Plasma in Materials Fabrication, IEEE Press (N.Y C 1994).

[2] Dony M.F., Ricard A., Dauchot J.P., Hecq M. and Wautelet M., Optical diagnostics of d.c. and RF argon magnetron discharges, Surface and Coatzngs Techn. 74-75 (1995) 479.

[3] Dony M.F , Ricard A., Wautelet M., Dauchot J.P and Hecq M., Comparison of DC and RF argon magnetron discharges by optical emission and absorption spectroscopy, $J$. Vac. Scr. Techn., in press

[4] Minea T M., Bretagne J , Magne L., Pagnon D. and Touzeau M., Spectroscopic Evidence of the Ceramics Erosion in a Stationary Plasma Thruster, to appear in the Proceedings (ESA- SP-398) of $2^{\text {nd }}$ European Spacecraft Propulsion Conf. 27-29 May 1997 (Noordwijk, Netherlands).

[5] Aymar M. and Coulombe M., Theoretical Transition Probabilities and Lifetimes in KrI and XeI Spectra, Atomıc Data and Nuclear Data Tables 21 (1978) 537.

[6] Sabbagh J. and Sadeghi N., Experimental Transition Probabilities of some Xe (I) lines, $J$. Quant. 'Speqtrosc. and Radiat. Transfer 17 (1977) 297.

[7] Medhi T., Legrand P.B., Dauchot J.P., Wautelet M. and Hecq M., Optical emission diagnostics of an RF magnetron sputtering discharge, Spectrochım. Acta B 48 (1993) 1023. 